\title{
PEMODELAN JUMLAH KEMATIAN NEONATAL DI PROVINSI SULAWESI SELATAN MENGGUNAKAN REGRESI POISSON INVERSE GAUSSIAN
}

\author{
Irwan*, Wahidah Alwi, Nurhasanah \\ Jurusan Matematika \\ Fakultas Sains dan Teknologi UIN Alauddin Makassar \\ J1. Sultan Alauddin No. 63, Kabupaten Gowa, Sulawesi Selatan. 92113 \\ *E-mail: irwan.msi@uin-alauddin.ac.id
}

\begin{abstract}
Abstrak: Kematian neonatus adalah kematian bayi yang lahir hidup sampai dengan 28 hari sejak lahir. Angka kematian neonatal di Provinsi Sulawesi Selatan pada tahun 2018 masih cukup tinggi yaitu sebanyak 799 kasus. Oleh karena itu, diperlukan suatu analisis untuk mengetahui faktor-faktor apa saja yang berpengaruh signifikan terhadap jumlah kematian neonatus. Dalam penelitian ini, jumlah kematian neonatus dapat dimodelkan dengan menggunakan analisis regresi Poisson. Namun pada model ini terdapat masalah overdispersi sehingga analisis dilanjutkan dengan menggunakan analisis regresi Gaussian inverse Poisson sehingga diperoleh hasil hanya satu variabel yang berpengaruh signifikan terhadap jumlah kematian neonatus yaitu variabel persalinan ditolong oleh tenaga kesehatan $\left(x \rrbracket \_7\right)$ ). Model regresi Gaussian inverse Poisson yang diperoleh untuk jumlah kematian neonatus di Provinsi Sulawesi Selatan tahun 2018 adalah $\hat{\mu}=\exp (4,97785-$ $\left.0,11603 x_{7}\right)$.
\end{abstract}

Kata Kunci: kematian neonatal, overdispersi, regresi Poisson, regresi Poisson Inverse Gaussian

\section{PENDAHULUAN}

B erdasarkan hasil Survei Demografi dan Kesehatan Indonesia Tahun 2017 memperlihatkan adanya penurunan kematian neonatal, dimana kematian neonatal turun dari 32 per 1.000 kelahiran hidup hasil Survei Demografi dan Kesehatan Indonesia Tahun 1991 menjadi 15 per 1.000 kelahiran hidup hasil Survei Demografi dan Kesehatan Indonesia Tahun 2017 (Arniva, 2018). Berdasarkan hasil pengumpulan data Dinas Kesehatan Sulawesi Selatan Tahun 2019 menunjukkan penurunan dari Tahun 2015 sebesar 917 kasus yaitu 6,12 per 1.000 kelahiran hidup menjadi 799 kasus atau 5,3 per 1000 kelahiran kehidupan di Tahun 2018. Kasus kematian neonatal merupakan kejadian yang berdistribusi poisson, sehingga dalam pemodelannya bisa menggunakan regresi poisson. Tetapi, kasus ini berpotensi mengalami pelanggaran asumsi equidispersi namun sering dijumpai kasus overdispersi. Sehingga, dalam penanganannya dilakukan pengembangan model yaitu dengan menggunakan Regresi Poisson Inverse Gaussian.

Ada banyak penelitian yang menggunakan model Regresi PIG untuk mengatasi kondisi overdispersi yaitu Herindrawati dan Widiari sama-sama melakukan penelitian dengan metode regresi PIG dengan hasil yang diperoleh masing-masing yaitu terdapat faktor-faktor yang mempengaruhi penyakit HIV di Jawa Tengah secara signifikan yaitu presentase PUS yang menggunakan kondom, rasio fasilitas kesehatan, presentase daerah 
perkotaan, presentase penduduk usia 25-34 tahun (Herindrawati et.al., 2017). Faktorfaktor yang mempengaruhi jumlah kasus baru HIV di Jawa Timur secara signifikan yaitu persentase PUS yang menggunakan kondom, persentase penduduk dengan pendidikan terakhir SLTA, dan rasio fasilitas Kesehatan (Heller et al., 2019). Tremblay melakukan penelitian dengan hasil yaitu didapatkan pemodelan sistem bonus-molus dalam asuransi mobil dengan meminimalkan risiko pihak asuransi (Herindrawati et al., 2017). Shoukri et al, Putri et al, dan Liteng Zha melakukan penelitian yang sama yaitu membandingkan metode PIG dengan regresi binomial negatif pada masing-masing kasus yaitu pada kasus mastitis dalam sampel peternakan sapi perah di Intario, kasus data kepiting tapal kuda dan pada kasus jumlah kecelakaan motor di dua tempat yaitu Texas dan Washington (Shoukri et al., 2004). Dean et al dan Ouma et al, melakukan penelitian yang sama dengan hasil yang didapatkan yaitu pemodelan terbaik dengan metode regresi PIG dalam menghitung nilai semu/momen pada data klaim asuransi mobil dan pada kasus data penyakit menular (Dean, 1989; Ouma et al., 2016). Gillian Z. Heller et al., dalam penelitiannya mampu memodelkan efek perlakuan pada parameter mean dan dispersi yang signifikan pada kasus penyakit parkinson serta dilakukan juga dengan memperhatikan parametrikisasi ortogonal dari distribusi PIG (Heller et al., 2019). Katsuhito Nohara dan Masaki Narukawa melakukan penelitian dengan hasil yaitu fungsi permintaan rekreasi Prefektur Fukushima mengalami kerugian sebesar 2,85 triliun selama tiga tahun terakhir (Nohara et al., 2015).

Sebaran poisson hanya bergantung pada rata-rata banyaknya hasil percobaan yang terjadi selama selang waktu atau daerah yang diberikan. Sehingga sebaran poisson memiliki fungsi peluang sebagai berikut:

$$
p(y ; \mu)=\frac{e^{-\mu} \mu^{y}}{y !} ; y=0,1,2, \ldots ; \mu>0 \text {. }
$$

Pada model regresi Poisson terdapat asumsi yang harus dipenuhi yaitu overdispersi dimana $\operatorname{Var}(Y)>E(Y)$. Selanjutnya digunakan model regresi Poisson Inverse Gaussian dengan persamaan:[2]

$$
\mu_{i}=e^{\mathrm{X}_{\mathrm{i}}^{\mathrm{T}} \beta} \text { atau } \ln \left(\mu_{i}\right)=\mathbf{X}_{i}^{T} \boldsymbol{\beta} .
$$

Estimasi parameter $\beta$ pada regresi Poisson Inverse Gaussian ditaksir dengan metode maximum likelihood, dengan menentukan fungsi likelihood dari distribusi Poisson Inverse Gaussian sebagai berikut:[2]

$$
\begin{gathered}
L(\boldsymbol{\beta} ; \tau)=\prod_{i=1}^{n} P\left(Y=y_{i} \mid x_{i} ; \boldsymbol{\beta} ; \tau\right), \\
L(\boldsymbol{\beta} ; \tau)=\prod_{i=1}^{n}\left\{\frac{\mu_{i}^{y_{i}} e^{\frac{1}{\tau}}}{y_{i} !}\left(\frac{2}{\pi \tau}\right)^{\frac{1}{2}}\left(2 \mu_{i} \tau+1\right)^{-\frac{\left(y_{i}-\frac{1}{2}\right)}{2}} K_{s_{i}}\left(z_{i}\right)\right\} .
\end{gathered}
$$

Statistik uji yang digunakan yaitu pengujian secara overall mencakup seluruh parameter $\beta$ secara bersama-sama dengan hipotesis:

$H_{0}: \beta_{1}=\beta_{2}=\beta_{3}=\cdots=\beta_{k}=0$.

$H_{1}$ : paling tidak ada satu $\beta_{j} \neq 0 ; j=1,2,3, \ldots, k$.

Statistik uji

$G^{2}=-2 \log \left(\frac{L_{o}}{L_{1}}\right)$; Dengan daerah penolakannya adalah tolak $\mathrm{H}_{0}$ jika $G^{2}>\chi_{(k ; \alpha)}^{2}$.

Uji yang kedua yaitu uji parsial digunakan untuk mengetahui pengaruh variabel independen dan konstanta terhadap variabel dependen secara individu. 
$H_{0}: \beta_{j}=0$.

$H_{1}: \beta_{j} \neq 0$.

$Z=\frac{\widehat{\beta}_{j}}{S E\left(\widehat{\beta}_{j}\right)}$.

Keputusan, tolak $\mathrm{H}_{0}$ jika statistik $\left|\mathrm{z}_{\mathrm{hit}}\right|>\mathrm{z}_{\alpha / 2}=1,96$ dan nilai $p$-value $<\alpha$, dimana nilai $\alpha=0,05$.

Salah satu kriteria informasi dalam pemilihan model terbaik yaitu dengan melihat nilai Akaike Information Criteria (AIC) terkecil. Dengan persamaan sebagai berikut:

$$
A I C=2 k-2 \ln (L(\hat{\theta})) .
$$

\section{METODE PENELITIAN}

Data yang digunakan adalah data sekunder yang diperoleh dari Dinas Komunikasi, Informatika, Statistik dan Persandian (DISKOMINFO-SP) Provinsi Sulawesi Selatan Tahun 2018. Dengan variabel penelitian yaitu Kematian neonatal (Y), Berat badan lahir rendah $\left(\mathrm{X}_{1}\right)$, Cakupan pelayanan kesehatan pada ibu hamil $\mathrm{K} 1\left(\mathrm{X}_{2}\right)$, Cakupan pelayanan kesehatan pada ibu hamil K4 $\left(\mathrm{X}_{3}\right)$, Pemberian tablet $\mathrm{Fe}^{3}$ (90 tablet) pada ibu hamil $\left(\mathrm{X}_{4}\right)$, Penanganan komplikasi kebidanan $\left(\mathrm{X}_{5}\right)$, Pelayanan kesehatan bayi $\left(\mathrm{X}_{6}\right)$, dan Persalinan ditolong tenaga kesehatan $\left(X_{7}\right)$. Adapun Langkah-langkah analisis yang dilakukam dalam penelitian ini adalah sebagai berikut: (1) Mengambil data terkait dengan jumlah kematian neonatal yang diperoleh dari Diskominfo-SP Sulawsi Selatan Tahun 2018; (2) Mendeskripsikan data; (3) Mendapatkan model regresi poisson dengan langkah-langkah sebagai berikut: (a) Menentukan nilai taksiran parameter regresi poisson; dan (b) Menentukan model regresi poisson; (4) Memeriksa adanya overdispersi dari model regresi poisson. Jika terdapat overdispersi dari model regresi poisson makan dapat dilakukan pendekatan model regresi Poisson Inverse Gaussian; (5) Mendapatkan model regresi Poisson Invers Gaussian dengan langkah-langkah sebagai berikut: (a) Menentukan nilai taksiran parameter regresi Poisson Invers Gaussian; (b) Menentukan model regresi Poisson Invers Gaussian; dan (c) Menguji signifikansi parameter regresi Poisson Invers Gaussian dengan uji overall dan uji parsial; (5) Menentukan faktor-faktor yang berpengaruh dengan langkah-langkah sebagai berikut: (a) Menentukan model regresi terbaik berdasarkan nilai AIC yang terkecil; (b) Menentukan faktor-faktor yang berpengaruh dengan melihat variabel-variabel yang signifikan berdasarkan model regresi terbaik; dan (c) Menginterpretasikan model regeresi terbaik yang diperoleh.

\section{HASIL DAN PEMBAHASAN}

\section{Statistika Deskriptif}

Tabel 1. Statistika Deskriptif

\begin{tabular}{ccccc}
\hline Variabel & Minimum & Maksimum & Rata-rata & Variansi \\
\hline $\mathrm{Y}$ & 4,00 & 79,00 & 33,29 & 424,30 \\
$\mathrm{X}_{1}$ & 2,28 & 7,92 & 4,65 & 2,28 \\
$\mathrm{X}_{2}$ & 72,62 & 105,98 & 97,42 & 40,42 \\
$\mathrm{X}_{3}$ & 62,86 & 99,21 & 87,72 & 69,54 \\
$\mathrm{X}_{4}$ & 59,92 & 103,53 & 87,10 & 80,91 \\
$\mathrm{X}_{5}$ & 33,80 & 99,00 & 78,17 & 200,62 \\
\hline
\end{tabular}




\begin{tabular}{lllll}
\hline $\mathrm{X}_{6}$ & 74,81 & 101,52 & 95,46 & 37,27 \\
$\mathrm{X}_{7}$ & 66,36 & 103,09 & 91,96 & 50,78 \\
\hline
\end{tabular}

Berdasarkan Tabel 1 diketahui bahwa rata-rata jumlah kematian neonatal di Provinsi Sulawesi Selatan Tahun 2018 sebanyak 33 jiwa, dengan nilai variansi sebesar 424,30 yang berarti bahwa nilai tersebut lebih besar dari nilai tengahnya (rata-rata) yang datanya menyebar atau dengan kata lain memiliki pencilan.

\section{Model Regresi Poisson}

$$
\begin{gathered}
\ln \left(\hat{\mu}_{i}\right)=\beta_{0}+\beta_{1} X_{1}+\beta_{2} X_{2}+\beta_{3} X_{3}+\beta_{4} X_{4}+\beta_{5} X_{5}+\beta_{6} X_{6}+\beta_{7} X_{7}, \\
\left(\hat{\mu}_{i}\right)=\exp \left(\beta_{0}+\beta_{1} X_{1}+\beta_{2} X_{2}+\beta_{3} X_{3}+\beta_{4} X_{4}+\beta_{5} X_{5}+\beta_{6} X_{6}+\beta_{7} X_{7}\right), \\
\left(\hat{\mu}_{i}\right)=\exp \left(3,8212749-0,1128314 X_{1}+0,1109800 X_{2}+0,0144058 X_{3}-0,0120299 X_{4}+\right. \\
\left.0,0078782 X_{5}-0,0001554 X_{6}-0,1248054 X_{7}\right) .
\end{gathered}
$$

Untuk dapat menggunakan model tersebut, maka terdapat asumsi yang harus dipenuhi yaitu nilai variansi harus lebih besar dari nilai rataannya (mean) yang disebut overdispersi. Maka langkah selanjutnya dilakukan uji overdispersi untuk mengetahui apakah terjadi pelanggaran asumsi dalam regresi Poisson.

\section{Overdispersi}

Dari hasil analisis deskriptif pada Tabel 1 diperoleh bahwa nilai variansi data penelitian lebih besar dari rata-ratanya (mean). Dimana nilai variansinya sebesar 424,30 lebih besar dari nilai rata-ratanya yakni sebesar 33,29 sehingga dapat dinyatakan bahwa data penelitian ini mengalami overdispersi. Terjadinya overdispersi menyebabkan model pada regresi Poisson tidak dapat digunakan maka salah satu model alternatif untuk mengatasi overdispersi pada regresi Poisson yaitu dengan melakukan pendekatan regresi Poisson Inverse Gaussian.

\section{Pemodelan Regresi Poisson Inverse Gaussian}

Berdasarkan tujuh variabel yang digunakan dalam penelitian ini maka diperoleh lima kombinasi model yang sudah konvergen sebagai berikut:

$$
\begin{aligned}
\mu_{i} & =\exp \left(\beta_{0}+\beta_{1} X_{1}+\beta_{2} X_{2}+\beta_{3} X_{3}+\beta_{4} X_{4}+\beta_{5} X_{5}+\beta_{6} X_{6}+\beta_{7} X_{7}\right) . \\
\mu_{i} & =\exp \left(\beta_{0}+\beta_{1} X_{1}+\beta_{2} X_{2}+\beta_{3} X_{3}+\beta_{4} X_{4}+\beta_{5} X_{5}+\beta_{7} X_{7}\right) . \\
\mu_{i} & =\exp \left(\beta_{0}+\beta_{1} X_{1}+\beta_{2} X_{2}+\beta_{3} X_{3}+\beta_{5} X_{5}+\beta_{7} X_{7}\right) . \\
\mu_{i} & =\exp \left(\beta_{0}+\beta_{1} X_{1}+\beta_{2} X_{2}+\beta_{5} X_{5}+\beta_{7} X_{7}\right) . \\
\mu_{i} & =\exp \left(\beta_{0}+\beta_{1} X_{1}+\beta_{2} X_{2}+\beta_{7} X_{7}\right) .
\end{aligned}
$$

\begin{tabular}{|c|c|c|c|c|c|c|c|c|c|}
\hline Variabel dari model & $\beta_{0}$ & $\beta_{1}$ & $\beta_{2}$ & $\beta_{3}$ & $\beta_{4}$ & $\beta_{5}$ & $\beta_{6}$ & $\beta_{7}$ & $\tau$ \\
\hline$x_{1}, x_{2}, x_{3}, x_{4} x_{5}, x_{6}, x_{7}$ & 3,784651 & $-0,100398$ & 0,092557 & 0,030959 & $-0,012756$ & 0,011515 & 0,007705 & $-0,131894$ & $-1,2694$ \\
\hline$x_{1}, x_{2}, x_{3}, x_{4} x_{5}, x_{7}$ & 4,161295 & $-0,102606$ & 0,090254 & 0,029744 & $-0,010896$ & 0,011108 & & $-0,125708$ & $-1,2689$ \\
\hline$x_{1}, x_{2}, x_{3}, x_{5}, x_{7}$ & 4,375447 & $-0,117018$ & 0,087624 & 0,022168 & & 0,010259 & & $-0,126881$ & $-1,2554$ \\
\hline$x_{1}, x_{2}, x_{5}, x_{7}$ & 4,498243 & $-0,137173$ & 0,095377 & & & 0,008734 & & $-0,112926$ & $-1,215$ \\
\hline$x_{1}, x_{2}, x_{7}$ & 4,97785 & $-0,12359$ & 0,09981 & & & & & $-0,11603$ & $-1,1608$ \\
\hline
\end{tabular}

Sebelum menentukan model terbaiknya maka perlu dilakukan penaksiran dan pengujian parameter.

Tabel 2. Estimasi parameter kemungkinan model regresi Poisson Inverse Gaussian 


\section{Pengujian Hipotesis}

Pengujian hipotesis yang digunakan ada dua bagian yaitu pengujian parameter secara serentak dan pengujian parameter secara parsial.

1. Pengujian parameter secara serentak

Pengujian parameter secara serentak dilakukan pada kemungkinan model yang sesuai dengan modek regresi Poisson Inverse Gaussian. Pada uji hipotesis ini dapat dilihat dari nilai statistik $\mathrm{G}$ dengan hipotesis berikut:

$\mathrm{H}_{\mathrm{o}}: \beta_{1}=\beta_{2}=\cdots=\beta_{7}=0$.

$\mathrm{H}_{1}$ : Paling sedikit ada satu $j$ dengan $\beta_{j} \neq 0 ; j=1,2, \ldots, 7$.

Tabel 3. Pengujian secara serentak

\begin{tabular}{ccccc}
\hline Variabel dari model & Statistik G & $\mathbf{V}$ & $\boldsymbol{X}_{(\boldsymbol{a} . \boldsymbol{v})}^{\mathbf{2}}$ & Keputusan \\
\hline$x_{1}, x_{2}, x_{3}, x_{4} x_{5}, x_{6}, x_{7}$ & 199,6464 & 17 & 27,58 & Tolak $H_{0}$ \\
$x_{1}, x_{2}, x_{3}, x_{4} x_{5}, x_{7}$ & 199,7184 & 18 & 28,86 & Tolak $H_{0}$ \\
$x_{1}, x_{2}, x_{3}, x_{5}, x_{7}$ & 199,9691 & 19 & 30,14 & Tolak $H_{0}$ \\
$x_{1}, x_{2}, x_{5}, x_{7}$ & 200,7759 & 20 & 31,41 & Tolak $H_{0}$ \\
$x_{1}, x_{2}, x_{7}$ & 201,8638 & 21 & 32,67 & Tolak $H_{0}$ \\
\hline
\end{tabular}

Berdasarkan Tabel 3 ditunjukkan jika nilai statistik uji G untuk semua kemungkinan model lebih besar dari nilai chi kuadrat. Sehingga kesimpulan uji overall model regresi Poisson Inverse Gaussian adalah tolak $H_{0}$ yang berarti bahwa paling sedikit terdapat satu parameter yang berpengaruh secara signifikan terhadap kematian neonatal.

2. Pengujian parameter secara individu

Hipotesis pengujian parameter secara individu sebagai berikut:

Tabel 4 Pengujian secara individu

\begin{tabular}{cc}
\hline Variabel dari model & Parameter Signifikan \\
\hline$x_{1}, x_{2}, x_{3}, x_{4}, x_{5}, x_{6}, x_{7}$ & $\beta_{7}$ \\
$x_{1}, x_{2}, x_{3}, x_{4} x_{5}, x_{7}$ & $\beta_{7}$ \\
$x_{1}, x_{2}, x_{3}, x_{5}, x_{7}$ & $\beta_{7}$ \\
$x_{1}, x_{2}, x_{5}, x_{7}$ & $\beta_{7}$ \\
$x_{1}, x_{2}, x_{7}$ & $\beta_{7}$ \\
\hline
\end{tabular}

Tabel 4 menunjukkan bahwa model dengan parameter yang signifikan adalah model yang memenuhi daerah kritis atau memiliki p-value kurang dari taraf signifikan yaitu $\alpha=0,05$ sehingga keputusan tolak $\mathrm{H}_{0}$ yang berarti parameter $\beta_{i}$ berpengaruh signifikan terhadap model atau dngan melihat nilai $Z_{\text {hitung }}$ yang dibandingkan dengan $\mathrm{z}_{\alpha / 2}=1,96$. 
Tabel 5. Nilai AIC dari model regresi PIG

\begin{tabular}{cl}
\hline Variabel dari model & AIC \\
\hline$x_{1}, x_{2}, x_{3}, x_{4} x_{5}, x_{6}, x_{7}$ & 217,6464 \\
$x_{1}, x_{2}, x_{3}, x_{4} x_{5}, x_{7}$ & 215,7184 \\
$x_{1}, x_{2}, x_{3}, x_{5}, x_{7}$ & 213,9691 \\
$x_{1}, x_{2}, x_{5}, x_{7}$ & 212,7759 \\
$x_{1}, x_{2}, x_{7}$ & 211,7541 \\
\hline
\end{tabular}

Berdasarkan Tabel 5 dapat dilihat bahwa terdapat nilai AIC untuk setiap kemungkinan model. Dari tabel tersebut dapat diketahui model regresi Poisson Inverse Gaussian yang memiliki nilai AIC terkecil yaitu pada model kelima dengan nilai AIC $=211,7541$ dengan variabel $x_{1}, x_{2}$, dan $x_{7}$. Berdasarkan model tersebut maka diperoleh estimasi parameter model regresi Poisson Inverse Gaussian pada Tabel 6.

Tabel 6. Penaksiran parameter model regresi PIG

\begin{tabular}{ccccc}
\hline Parameter & Taksiran & $\begin{array}{c}\text { Stand. } \\
\text { Error }\end{array}$ & $\boldsymbol{Z}_{\text {hitung }}$ & p-value \\
\hline$\beta_{0}$ & 4,97785 & 1,97269 & 2,523 & 0,0207 \\
$\beta_{1}$ & $-0,12359$ & 0,07949 & $-1,555$ & 0,1365 \\
$\beta_{2}$ & 0,09981 & 0,05743 & 1,738 & 0,0984 \\
$\beta_{7}$ & $-0,11603$ & 0,05172 & $-2,243$ & 0,0370 \\
$\tau$ & $-1,1608$ & 0,3818 & $-3,04$ & 0,00673 \\
\hline
\end{tabular}

Berdasarkan Tabel 6 dapat dilihat bahwa variabel prediktor yang berpengaruh signifikan terhadap model jumlah kemataian neonatal yaitu variabel persalinan ditolong tenaga kesehatan $\left(x_{7}\right)$ dengan nilai $p$-value sebesar 0,0370 yang kurang $\alpha=0,05$ sehingga hipotesisnya $\mathrm{H}_{0}$ ditolak. Dan dari variabel yang signifikan tersebut maka diperoleh model regresi Poisson Inverse Gaussian berikut:

$$
\hat{\mu}=\exp \left(\beta_{0}-\beta_{7} x_{7}\right) \text {. }
$$

Berdasarkan model tersebut, dapat dilihat bahwa nilai taksiran parameter model untuk variabel persalinan ditolong tenaga kesehatan $\left(x_{7}\right)$ bernilai negatif. Hal ini menunjukkan bahwa hubungan antara variabel tersebut dengan log rata-rata dari jumlah kematian neonatal berbanding terbalik. Artinya apabila persentase ditolong tenaga kesehatan meningkat maka log rata-rata kasus kematian neonatal akan cenderung menurun.

Berdasarkan model regresi Poisson Inverse Gaussian yang diperoleh bahwa apabila tidak terdapat persalinan ditolong tenaga kesehatan maka jumlah kematian neonatal sebanyak exp:

$(4,97785)=145,16=145$ orang per 1.000 kelahiran hidup.

Untuk variabel $x_{7}$, apabila setiap persalinan yang ditolong tenaga kesehatan meningkat, maka jumlah kematian neonatal berkurang sebanyak exp $(-0,11603)=0,890$, sehingga dengan semakin banyaknya jumlah persalinan yang ditolong langsung oleh tenaga kesehatan maka rata-rata jumlah kematian neonatal menurun $0,890(100 \%)=89 \%$ 


\section{KESIMPULAN}

Adapun kesimpulan dari penelitian ini yaitu diperoleh model regresi Poisson Inverse Gaussian untuk kasus kematian neonatal di Provinsi Sulawesi Selatan Tahun 2018 yaitu sebagai berikut:

$$
\hat{\mu}=\exp \left(4,97785-0,11603 x_{7}\right) .
$$

Serta, berdasarkan hasil analisis regresi Poisson Inverse Gaussian, diketahui bahwa faktor yang berpengaruh secara signifikan terhadap jumlah kematian neonatal di Provinsi Sulawesi Selatan Tahun 2018 yaitu persentase persalinan ditolong tenaga kesehatan.

\section{DAFTAR PUSTAKA}

Arniva, N.S., Purhadi., \& Sutikno. (2018). Parameter Estimation and Statistical Test in Mixed Model of Geographically Weighted Bivariate Poisson Inverse Gaussian Regression. 2018 International Symposium on Advanced Intelligent Informatics (SAIN), 62-65.

Dean, C., Lawless, J.F., \& Willmot, G.E. (1989). A Mixed Poisson Inverse Gaussian Regression Model. The Canadian Journal of Statistics. 17(2), 171-181.

Heller, G.Z., Couturier., D-L., \& Heritier, S.R. (2019). Beyond Mean Modelling: Bias Due to Misspecification of Dispersion in Poisson Inverse Gaussian Regression. Biometrical Journal. 61(2), 333-342.

Herindrawati, A.Y. (2017). Pemodelan Regresi Poisson Inverse Gaussian Studi Kasus: Jumlah Kasus Baru HIV di Provinsi Jawa Tengah Tahun 2015. [Tesis]. Surabaya: Institut Teknologi Sepuluh Nopember.

Nohara, K \& Narukawa, M. (2015). Measuring Lost Recreational Benefits in Fukushima due to Harmful Rumors Using a Poisson Inverse Gaussian Regression. EconPapers.

Ouma, V.M., Mwalili, S.M., \& Kiberia, A.W. (2016). Poisson Inverse Gaussian (PIG) Model for Infectious Disease Count Data. American Journal of Theoretical and Applied statistics. 5(5), 326-333.

Purnamasari,I. (2016). Penaksiran Parameter dan Statistik Uji Dalam Model Regresi Geographically Weighted Poisson Inverse Gaussian. [Tesis]. Surabaya: Institut Teknologi Sepuluh Nopember.

Putri, G.N., Nurrohmah, S., \& Fithriani, I. (2017). Comparing Poisson Inverse Gaussian Model and Negative Binomial Model on case study: Horseshoe Crabs Data. Journal of Physics:Conference Series. 1442(1), 1-5.

Shoukri, M.M., Asyali, M.H., VanDorp, R., \& Kelton, D. (2004). The Poisson Inverse Gaussian Regression Model in the Analysis of Clustered Count Data. Journal Data Science. 2, 17-32.

Sundari, I. (2014). Regresi Poisson dan Penerapannya untuk Memodelkan Hubungan Usia dan Perilaku Merokok Terhadap Jumlah Kematian Penderita Penyakit Kanker Paru-Paru. Jurnal Matematika UNAND. 1(1), 71-76.

Tremblay, L. (1992). Using the Poisson Inverse Gaussian in Bonus-malus Systems. Journal ASTIN Bulletin. 22(1), 97-106

Widiari, S.M. (2016). Penaksiran Parameter aan Statistik Uji Dalam Model Regrsi Poisson Inverse Gaussian (PIG) Studi Kasus:Jumlah Kasus Baru HIV di Provinsi Jawa Timur Tahun 2013. [Tesis]. Surabaya: Institut Teknologi Sepuluh Nopember.

Windiarto, T., Yusuf, A.H., Santosa, A.D., Nugroho, S., Latifah, S., Solih, R., Hermawati, F., Purbasari, L.A., \& Rahmawatiningsih, A. (2018). Profil Anak Indonesia 2018. Jakarta: Kementrian Pemberdayaan Perempuan dan Perlindungan Anak (KPPPA).

Zha, L., Lord, D., \& Zou, Y. (2016). The Poisson Inverse Gaussian (PIG) generalized Linear Regression Model for Analyzing Motor Vehicle Crash Data. Journal of Transportation Safety \& Security. 8(1), 18-35. 